\title{
Silylative Pinacol Coupling Catalyzed by Nitrogen-Doped Carbon-Encapsulated Nickel/Cobalt Nanoparticles: Evidence for a Silyl Radical Pathway
}

\author{
Kramer, Søren; Hejjo, Fatima; Rasmussen, Kristoffer Hauberg; Kegnæs, Søren
}

Published in:

A C S Catalysis

Link to article, DOI:

10.1021/acscatal.7b02788

Publication date:

2018

Document Version

Peer reviewed version

Link back to DTU Orbit

Citation (APA):

Kramer, S., Hejjo, F., Rasmussen, K. H., \& Kegnæs, S. (2018). Silylative Pinacol Coupling Catalyzed by

Nitrogen-Doped Carbon-Encapsulated Nickel/Cobalt Nanoparticles: Evidence for a Silyl Radical Pathway. A C S Catalysis, 8, 754-759. https://doi.org/10.1021/acscatal.7b02788

\section{General rights}

Copyright and moral rights for the publications made accessible in the public portal are retained by the authors and/or other copyright owners and it is a condition of accessing publications that users recognise and abide by the legal requirements associated with these rights.

- Users may download and print one copy of any publication from the public portal for the purpose of private study or research.

- You may not further distribute the material or use it for any profit-making activity or commercial gain

- You may freely distribute the URL identifying the publication in the public portal 
This document is confidential and is proprietary to the American Chemical Society and its authors. Do not copy or disclose without written permission. If you have received this item in error, notify the sender and delete all copies.

\section{Silylative Pinacol Coupling Catalyzed by Nitrogen-Doped Carbon-Encapsulated Nickel/Cobalt Nanoparticles: Evidence for a Silyl Radical Pathway}

\begin{tabular}{|r|l|}
\hline Journal: & ACS Catalysis \\
\hline Manuscript ID & CS-2017-027889.R1 \\
\hline Manuscript Type: & Article \\
\hline Date Submitted by the Author: & 14-Nov-2017 \\
\hline Complete List of Authors: & $\begin{array}{l}\text { Kramer, Soren; Technical University of Denmark, Department of Chemistry } \\
\text { Hejjo, Fatima; Technical University of Denmark, Department of Chemistry } \\
\text { Rasmussen, Kristoffer; Technical University of Denmark, Department of } \\
\text { Chemistry } \\
\text { Kegnæs, Søren; Technical University of Denmark, Department of } \\
\text { Chemistry }\end{array}$ \\
\hline
\end{tabular}




\title{
Silylative Pinacol Coupling Catalyzed by Nitrogen-
}

\section{Doped Carbon-Encapsulated Nickel/Cobalt}

\section{Nanoparticles: Evidence for a Silyl Radical Pathway}

\author{
Søren Kramer, Fatima Hejjo, Kristoffer H. Rasmussen, Søren Kegnces* \\ Department of Chemistry, Technical University of Denmark, 2800 Kgs. Lyngby (Denmark).
}

\begin{abstract}
The silylative pinacol coupling of arylaldehydes catalyzed by an easily accessible, heterogeneous base-metal catalyst is demonstrated. Instead of using the classical combination of catalyst, stoichiometric metal reductants, and chlorosilanes, the developed reaction only requires the use of a catalyst and a hydrosilane, which serves as both reductant and silylating agent. A rare mechanistic investigation in this field focusing on the organic reactants was undertaken using various techniques including experimental rate orders, kinetic isotope effect, radical scavengers, and stoichiometric tests. The obtained results provided evidence for a reaction mechanism which is different from the classical pinacol coupling pathway. We propose that the heterogeneous catalyst facilitates easy access to silyl radicals thereby circumventing the usual need for explosive initiators to access these species. In addition, leaching tests and recycling of the catalyst were performed, clearly supporting the heterogeneous nature of the catalyst.
\end{abstract}


Keywords: Heterogeneous catalysis, nanoparticles, nitrogen-doped carbon, mechanism, silyl radicals

\section{INTRODUCTION}

The use of catalysis is widespread in the chemical industry due to its facilitation of energyefficient production.[1] In terms of sustainability, heterogeneous catalysis often displays significant advantages over homogeneous catalysis such as robustness, recyclability, and ease of catalyst separation.[2] However, compared to homogeneous molecular catalysis, the mode of operation of heterogeneous catalysts is much less well-understood. This feature often complicates rational reaction improvement and development. In this regard, insight into reaction pathways can be highly valuable.

Recently, significant research effort has demonstrated the use of base metal nanoparticles supported on nitrogen-doped carbon as powerful heterogeneous catalysts for a variety of organic transformations. [3,4] In addition to the methodology development, most reports also study the physical properties of these novel materials.[4] In contrast, very limited knowledge is available regarding the underlying pathways that these materials are invoking on the organic reactants. These pathways are rarely studied; more commonly, they are simply presumed to parallel their counterparts from homogeneous catalysis.[5]

Formation of carbon-carbon bonds is central to organic synthesis for the production of pharmaceuticals, materials, and fuels.[6] In addition, 1,2-diols are prevalent intermediates in synthesis of fine chemicals, such as pharmaceuticals and agrochemicals, as well as starting points for bulk production of for example polyesters.[7] The pinacol coupling forms a new 
carbon-carbon bond and a 1,2-diol through an overall reduction of two carbonyl moieties.[8,9] Due to its reductive nature, the reaction is usually performed with a stoichiometric metal reductant and a silicon electrophile, in addition to the catalyst (Scheme 1a). In terms of wasteminimization, a more direct approach can be envisioned by using a simple hydrosilane as both reductant and silylating agent. Such a reaction protocol could potentially be achieved by a silyl radical mechanism. Unfortunately, the controlled formation of silyl radicals often requires elaborate conditions (Scheme 1b).[10] Radical initiators such as AIBN or peroxides are required. These compounds are explosive, thus placing demands on handling and storage. In addition to the single-use radical initiator, stoichiometric tin hydrides and specialized reagents such as $\mathrm{PhSeSiMe}_{3}$ or expensive silanes such as $\mathrm{HSi}(\mathrm{TMS})_{3}$ are often needed.[10,11] The development of a stable and recyclable catalyst circumventing the need for explosive, single-use initiators would be highly beneficial, especially, if it is operational with simple silanes such as $\mathrm{HSiEt}_{3}$.

Scheme 1. (a) Classical approach to pinacol coupling. (b) Typical reaction conditions for accessing silyl radicals

a) Classical methods for pinacol coupling

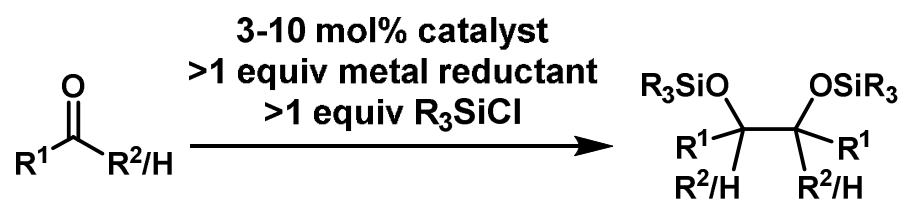

b) Hydrosilylation through addition of silyl radicals to ketones $10 \mathrm{~mol} \%$ AIBN

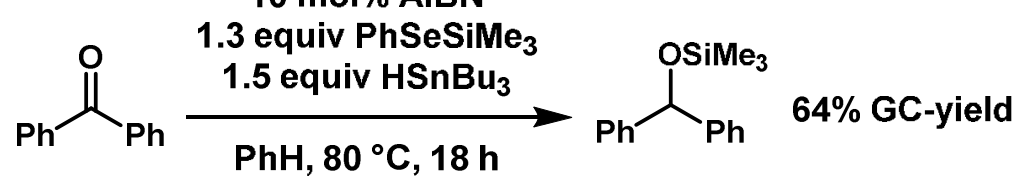

Herein, we report the reaction development of a silylative pinacol coupling of arylaldehydes using $\mathrm{HSiEt}_{3}$ without the need for an additional stoichiometric reductant or explosive radical 
initiators. The recyclable, heterogeneous catalyst consists of base metal nanoparticles on nitrogen-doped carbon. The ensuing mechanistic study of the organic reactants provided experimental evidence which is consistent with initial silyl radical formation. In contrast, an alternative pathway proceeding through an initial pinacol coupling followed by silylation is inconsistent with the obtained data.

\section{RESULTS AND DISCUSSION}

The study was initiated by the development of a catalytic protocol with easily accessible nickel/cobalt alloy nanoparticles encapsulated in nitrogen-doped carbon $\left(\mathrm{Ni}_{1} \mathrm{Co}_{1} @ \mathrm{NC}\right) .[12,13]$ Under the optimized conditions, using 8 mol\% $\mathrm{Ni}_{1} \mathrm{Co}_{1} @ \mathrm{NC}$ (4 mol\% of each metal), the desired product, 1a, was observed in $79 \%$ yield (Table 1, entry 1). The product from direct hydrosilylation, 2, accounted for the remaining mass balance. Control experiments without either $\mathrm{Ni}_{1} \mathrm{Co}_{1} @ \mathrm{NC}$ or $\mathrm{HSiEt}_{3}$ led to minimal conversions, confirming the crucial role of both reaction components (entries $2-3$ ). Without benzoic acid added to the $>99.5 \%$ purity benzaldehyde, the reaction was less selective and more of the direct hydrosilylation product 2 was obtained (entry 4). In contrast, using less pure ( $92 \%$ purity by ${ }^{1} \mathrm{H}$ NMR), undistilled benzaldehyde without added benzoic acid resulted in comparable yields to the optimized conditions due to the inherent content of benzoic acid from autoxidation. Accordingly, careful purification of the aldehyde is not required. When the reaction was performed under air instead of inert atmosphere, a small decrease in yield was observed (entry 5). The difference between conversion and yield was determined to be formation of benzoic acid from aldehyde oxidation. However, the catalyst itself is only moderately sensitive to air.[14] Performing the reaction neat or in heptane instead of toluene had only a minor influence on the reaction outcome (entries 6-7), but a decrease in reaction temperature or silane equivalents led to a less efficient reaction (entries 8-9). Increasing 
the amount of silane to 2.5 equivalents did not increase the yield of 1 a compared to the standard conditions (entry 10).

\section{Table 1. Influence of Reaction Parameters on the Reaction Efficiency ${ }^{\text {a }}$}

\begin{tabular}{|c|c|c|c|c|}
\hline $5 \mathrm{~m}$ & 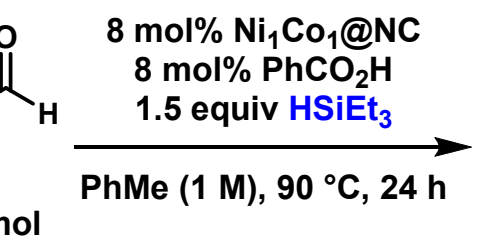 & & & $d^{\mathrm{SiE}}$ \\
\hline Entry & Change from standard cond. & conv. [\%] & Yield 1a [\%] & Yield 2 [\%] \\
\hline 1 & none & $>95$ & 79 & 20 \\
\hline 2 & no $\mathrm{Ni}_{1} \mathrm{Co}_{1} @ \mathrm{NC}$ & 5 & 0 & $<4$ \\
\hline 3 & no silane & 5 & $\mathbf{0}$ & $\mathbf{0}$ \\
\hline 4 & no $\mathrm{PhCO}_{2} \mathrm{H}$ & $>95$ & 54 & 38 \\
\hline 5 & reaction in air & 90 & 66 & 13 \\
\hline 6 & neat & $>95$ & 77 & 23 \\
\hline 7 & heptane instead of PhMe & $>95$ & 75 & 25 \\
\hline 8 & $70^{\circ} \mathrm{C}$ instead of $90^{\circ} \mathrm{C}$ & 63 & 33 & 7 \\
\hline 9 & 1.2 equiv $\mathrm{HSiEt}_{3}$ & 60 & 47 & 13 \\
\hline 10 & 2.5 equiv $\mathrm{HSiEt}_{3}$ & $>95$ & 72 & 22 \\
\hline
\end{tabular}

a Conversion and yield are based on ${ }^{1} \mathrm{H}$ NMR analysis with the aid of an internal standard. d.r. of $1 \mathrm{a}$ was 53:47 in all cases. $8 \mathrm{~mol} \% \mathrm{Ni}_{1} \mathrm{Co}_{1} @ \mathrm{NC}$ corresponds to $3.3 \mathrm{mg}$.

Recycling of the heterogenous catalyst under the standard conditions (Table 1, entry 1) was also examined. Since $\mathrm{Ni}_{1} \mathrm{Co}_{1} @ \mathrm{NC}$ is magnetic, separation of the catalyst from the reaction mixture is straightforward. Four consecutive reactions with the same catalyst, separated simply by magnetic filtration, demonstrated that the catalyst could be recycled (first run: 97\% conv., 79\% yield of 1a; second run: $98 \%$ conv., $81 \%$ yield of $1 \mathbf{a}$; third run: $95 \%$ conv., $71 \%$ yield of $1 \mathbf{a}$; fourth run: $80 \%$ conv., 54\% yield of 1a).[15] Further support for the heterogeneous nature of catalysis was provided by a hot filtration experiment. After seven hours of reaction, the reaction mixture was rapidly filtered under inert atmosphere and the resulting filtrate allowed to react for additional 17 


\begin{abstract}
hours. Analysis of the reaction mixture clearly showed that the liquid phase contained no catalytic activity.[16]
\end{abstract}

\title{
Scheme 2. Influence of Functional Groups on the Reaction Outcome ${ }^{\text {a }}$
}<smiles>[R]c1ccc(C(=O)c2ccc([R])cc2)cc1</smiles><smiles>CCOC(c1ccccc1)C(OCC)c1ccccc1</smiles>

$1 \mathrm{a}, 68 \%$<smiles>CCOC(c1ccc(C(C)C)cc1)C(OCC)c1ccc(C(C)C)cc1</smiles>

1c, $80 \%$<smiles>CCOC(c1cccc(F)c1)C(OCC)c1cccc(F)c1</smiles>

$1 e, 66 \%$<smiles>CCOC(c1ccc(C(F)(F)F)cc1)C(OCC)c1ccc(C(F)(F)F)cc1</smiles>

$1 \mathrm{~g}, 60 \%$<smiles>CCOC(c1cccc(Cl)c1)C(OCC)c1cccc(Cl)c1</smiles>

$1 \mathrm{~h}, 73 \%$<smiles>CCOC(c1ccc(C(C)(C)C)cc1)C(OCC)C(OCC)c1ccc(C(C)(C)C)cc1</smiles><smiles>CCOC(c1ccc(-c2ccccc2)cc1)C(OCC)c1ccc(-c2ccccc2)cc1</smiles>

1d, $72 \%$ 1f, $45 \%$<smiles>CCOC(c1ccc(OC)cc1)C(OCC)c1ccc(OC)cc1</smiles>

$1 \mathrm{i}, 10 \%^{\mathrm{b}}$<smiles>CCOC(c1ccncc1)C(OCC)c1ccncc1</smiles>

$1 \mathrm{j}, 0 \% \mathrm{~b}$

${ }^{a}$ Isolated yield of purified product. ${ }^{b}$ NMR yield. 
After having established effective conditions for the silylative pinacol coupling of benzaldehyde, the influence of functional groups was examined (Scheme 2). The unsubstituted benzaldehyde afforded $68 \%$ isolated yield of the desired product 1a. Introducing aliphatic or aromatic substituents on the substrate led to an increase in yield of the pinacol coupling products (1b-d). A substrate bearing a fluoride substituent in the meta position also provided the pinacol product in a good yield, however, using a para-fluoro-substituted substrate led to a small drop in yield (1e-f). In contrast, a para-trifluoromethyl group was well-tolerated (1g). Interestingly, a chlorosubstituted substrate led to $73 \%$ yield of pinacol coupling product without any trace of competing dehalogenation (1h). Finally, the use of para-methoxybenzaldehyde led to significantly reduced conversion and yield (1i). Whether this decrease is due to the coordinating features of the methoxy group or its strong electron-donating ability is unclear at this point, however, an electron poor substrate with a coordinating group (1j) also inhibited the reaction.[17]

With an efficient catalytic protocol as platform, we turned our attention to investigation of the reaction mechanism of the carbon-carbon bond forming pinacol reaction. Classically, the homogeneous reaction proceeds through two initial single electron transfers from the metal catalyst $\left(\mathrm{M}^{\mathrm{n}}\right)$ to two aldehydes affording two ketyl radicals bridged by the metal $\left(\mathrm{M}^{\mathrm{n}+2}\right)$. After dimerization of the metal-bound ketyl radicals, reaction with the chlorosilane releases the silylated pinacol product from the metal catalyst which subsequently is reduced by a stoichiometric metal reductant (Scheme 3a).[8] Although our reaction uses only a hydrosilane instead of a chlorosilane and a stoichiometric reductant, we first considered the possibility of an analogous classical pathway for our heterogeneous reaction. In this scenario, an initial reaction between catalyst and aldehyde would oxidize the metal nanoparticles and reduce the aldehyde 
forming a surface-bound ketyl radical. After dimerization of the ketyl radicals, reaction with the silane could liberate the silylated pinacol coupling product and a surface hydride. Release of $\mathrm{H}_{2}$ would ultimately reduce the catalyst and close the catalytic cycle (Scheme 3b). Several aspects of this pathway are very similar to recent reports in bimetallic homogeneous hydrosilylation.[18]

\section{Scheme 3. Classical Catalytic Cycles Proceeding through an Initial Pinacol Coupling Followed by Silylation}

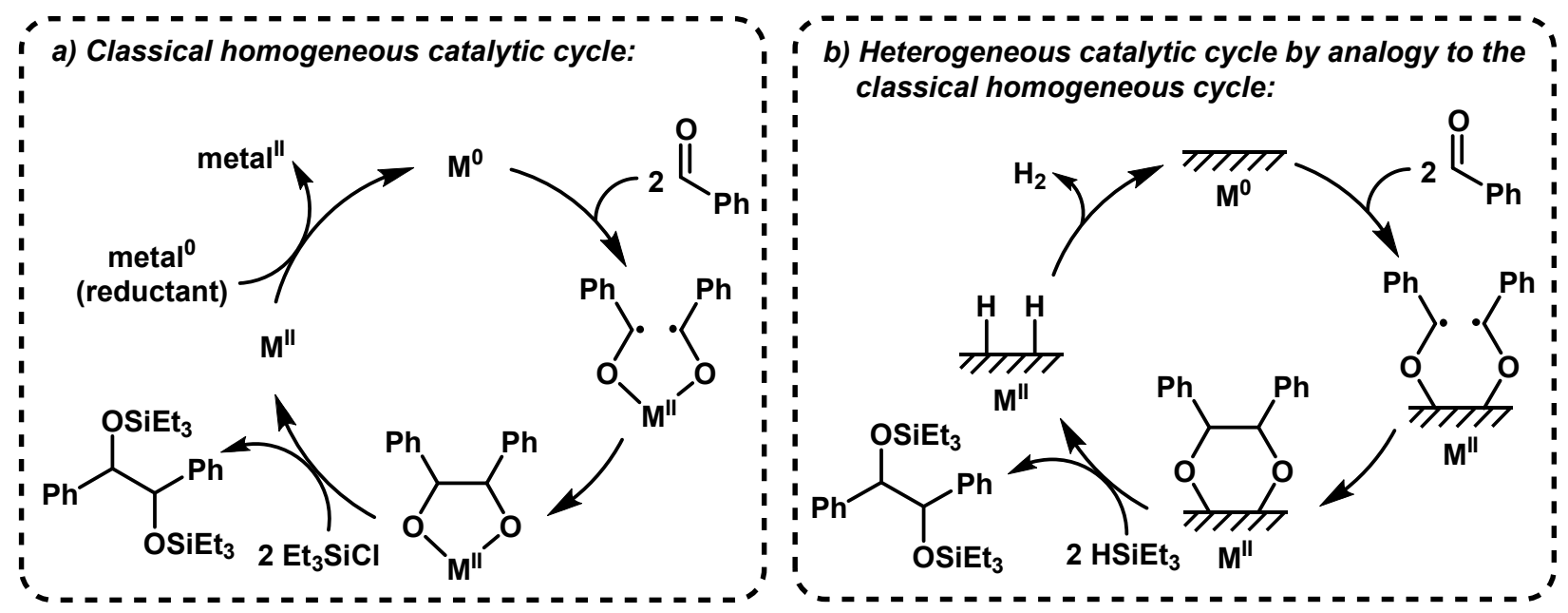

In line with this possible reaction pathway, Radivoy et al. have previously reported a pinacol coupling using cobalt nanoparticles in a noncatalytic fashion in the absence of a silane.[19] Under those conditions, the metal nanoparticles serve as the stoichiometric reductant. Surprisingly, for the $\mathrm{Ni}_{1} \mathrm{Co}_{1} @ \mathrm{NC}$ catalyst used here, the encapsulation of the metal alloy nanoparticles in nitrogen-doped carbon appears to protect them from such reactivity. In a stoichiometric experiment, one equivalent $\mathrm{Ni}_{1} \mathrm{Co}_{1} @ \mathrm{NC}$ was allowed to react with two equivalents of aldehyde in the absence of $\mathrm{HSiEt}_{3}$. After 24 hours at $90{ }^{\circ} \mathrm{C}$, essentially no reaction had occurred and the aldehyde was recovered (Scheme 4a). This result illustrates that reaction 
between aldehyde and $\mathrm{Ni}_{1} \mathrm{Co}_{1} @ \mathrm{NC}$ is unlikely as the first step in the catalytic cycle. Comparison of transmission electron microscopy (TEM) images of the catalyst material before use and after four consecutive catalytic reactions also
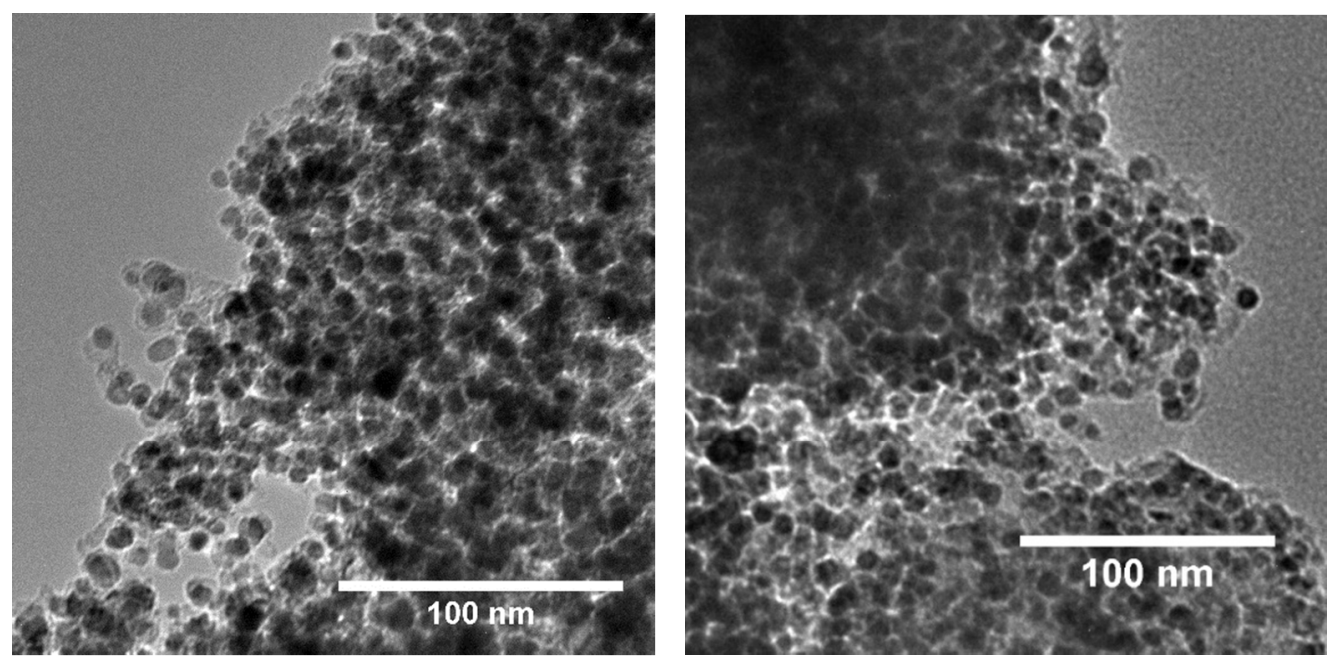

Figure 1. TEM image of unused catalyst (left) and catalyst after four cycles (right). The content, size, and distribution of the metal nanoparticles are unaffected by the reaction conditions.

\section{Scheme 4. Stoichiometric Studies}


a) Stoichiometric reaction without silane

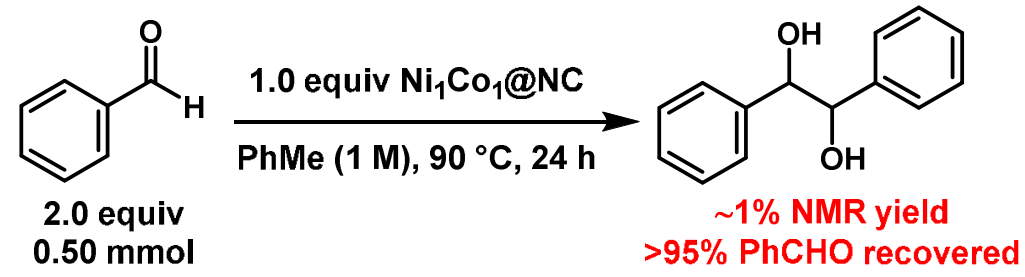

b) Testing for chemical competence of pinacol intermediate

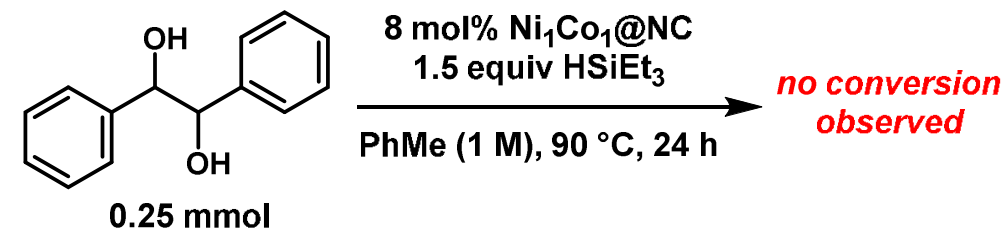

revealed no change in the metal nanoparticles (Figure 1). In addition, at the end of the four recycles, the effective catalyst loading can be considered $2 \mathrm{~mol} \%$, thus the metal cannot be the ultimate reductant. In combination, these results demonstrate that the metal in $\mathrm{Ni}_{1} \mathrm{Co}_{1} @ \mathrm{NC}$ is protected from the classical reactivity by the encapsulation in nitrogen-doped carbon.

Although the pinacol product was only observed in trace amounts (1\%) in the stoichiometric experiment, we evaluated if leaching of a metal pinacolate could serve as a highly active homogeneous catalyst. A reaction was performed in the absence of silane allowing for the potential formation of a soluble metal pinacolate. The reaction mixture was then filtered, to remove only the solid catalyst material, and $\mathrm{HSiEt}_{3}$ subsequently added. After additional 24 hours under the reaction conditions, no trace of the silylated pinacol coupling product (1a) was observed.[15]

As a final examination of the pinacol coupling/silylation pathway, we tested the chemical competency of hydrobenzoin, the authentic pinacol coupling product (Scheme 4b). After subjection to the reaction conditions, 1a could not be detected by ${ }^{1} \mathrm{H}$ NMR analysis. 
Accordingly, hydrobenzoin does not appear to be a productive intermediate on the reaction pathway.

Next, we focused on obtaining experimental rate orders for the homogenous reaction components. A preliminary time course investigation revealed an induction period of approximately one hour.[15] Accordingly, the initial rate measurements were made between two and four hours on the linear section after the induction period. Using this approach, it was found that the reaction is essentially zero order in benzaldehyde and nearly first order in $\mathrm{HSiEt}_{3}$ (Figure 2). These results exclude that reaction between benzaldehyde and silane is the rate-determining step and instead indicate that only the silane is involved between the ground state and the ratedetermining transition state. To further support this suggestion, the presence of a kinetic isotope effect was examined. By comparing the absolute rates in separate reaction vessels using either $\mathrm{HSiEt}_{3}$ or $\mathrm{DSiEt}_{3}$, a normal deuterium kinetic isotope effect $\left(k_{\mathrm{H}} / k_{\mathrm{D}}=1.9\right)$ was observed (Scheme 5).[15] The magnitude of the kinetic isotope effect indicates that the H-Si bond is either cleaved in the rate-determining step or reversible $\mathrm{H}-\mathrm{Si}$ cleavage is occurring on the pathway between the ground state of the catalyst and the turnover-limiting transition state. No isotope scrambling of the aldehyde hydrogen was observed in the recovered benzaldehyde, when using $\mathrm{DSiEt}_{3}$. 

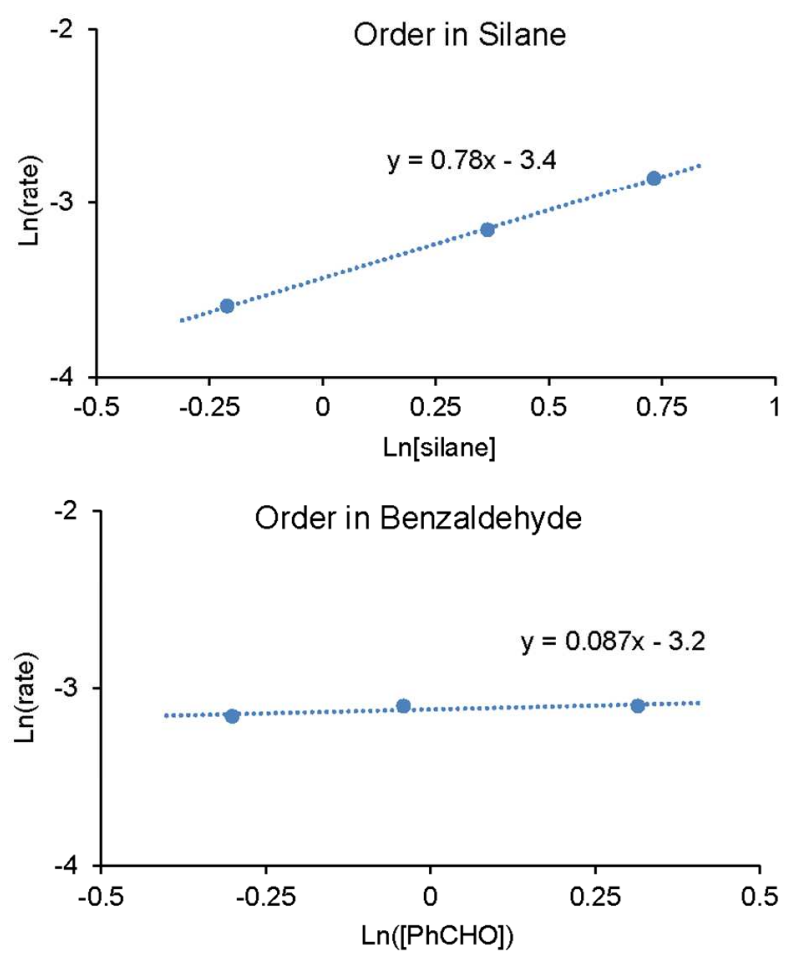

Figure 2. Determination of rate orders in $\mathrm{HSiEt}_{3}$ and benzaldehyde $\left(\mathrm{HSiEt}_{3}\right.$ 0.81-2.08 $\mathrm{M}$; PhCHO 0.74-1.37 M).

\section{Scheme 5. Detection of Kinetic Isotope Effect by Independent Rate Measurements}

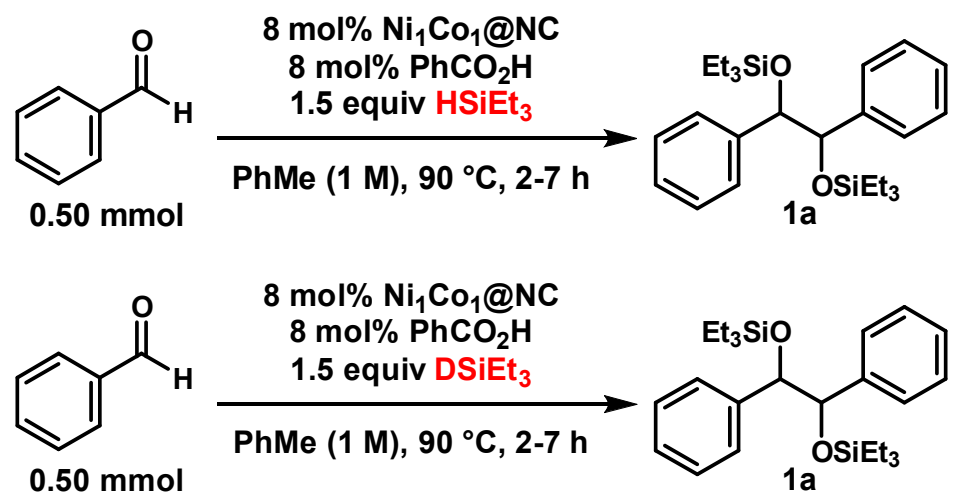

KIE = 1.9 (initial rates in separate vessels)

Finally, the possibility of a radical pathway was investigated. When a reaction was performed in the presence of 0.50 equivalents 2,2,6,6-tetramethylpiperidin-1-oxyl (TEMPO), no conversion of 
benzaldehyde had occurred after 5 hours (Scheme 6a). Instead significant amounts of a TEMPO$\mathrm{SiEt}_{3}$ adduct was observed. Repeating the reaction in the absence of benzaldehyde also afforded the TEMPO-SiEt ${ }_{3}$ adduct in 70\% yield (Scheme 6b). In contrast, no conversion of starting materials or formation of TEMPO-SiEt $3_{3}$ was observed in the absence of $\mathrm{Ni}_{1} \mathrm{Co}_{1} @ \mathrm{NC}$ (Scheme 6c).[15] The influence of 2,6-di-tert-butyl-4-methylphenol (BHT), a known radical inhibitor, on the standard reaction was also examined. The presence of $20 \mathrm{~mol} \%$ BHT completely prevented conversion of the aldehyde.[15] Overall, these results support the suggestion that silyl radicals are formed during the reaction and that a radical pathway is operating.

\section{Scheme 6. Experiments with TEMPO demonstrated Rapid Formation of TEMPO-SiEt Th $_{3}$ the Presence of $\mathrm{Ni}_{1} \mathrm{Co}_{1} @ \mathrm{NC}$.}

a)<smiles>O=Cc1ccccc1</smiles>

b)

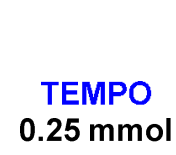

c)
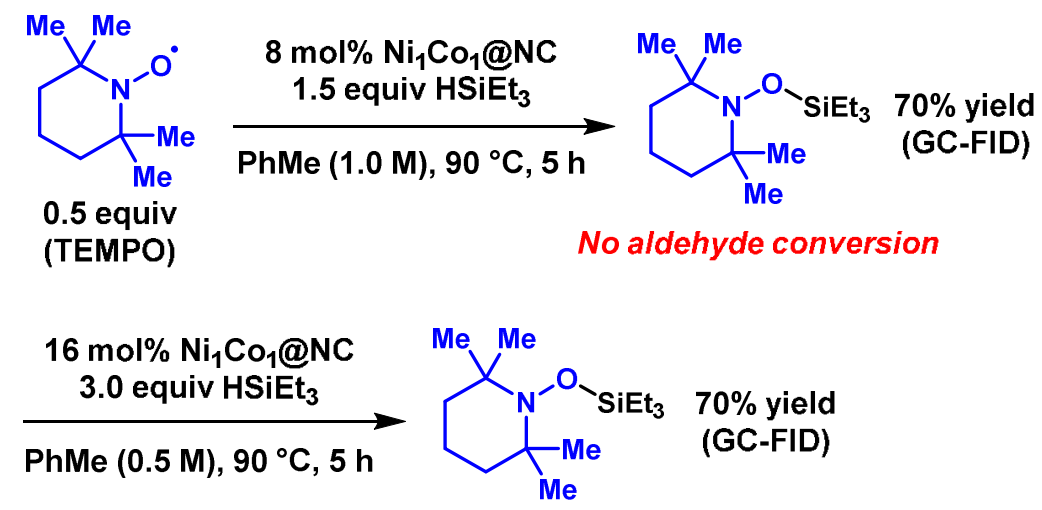

TEMPO $0.25 \mathrm{mmol}$

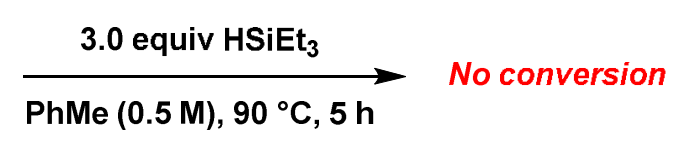

Collectively, the mechanistic investigations above present several inconsistencies with the pathway in Scheme 3b. A new pathway consistent with the mechanistic evidence presented above is illustrated in Scheme 7. Here, the $\mathrm{Ni}_{1} \mathrm{Co}_{1} @ \mathrm{NC}$ initially cleaves the $\mathrm{H}-\mathrm{Si}$ bond liberating a silyl radical. This radical can attack the oxygen atom of the aldehyde forming a highly stabilized benzylic radical.[10] The benzyl radical can then add to benzaldehyde, possibly, in a 
Brønsted acid-activated form which could explain the influence of benzoic acid on the selectivity.[20] Alternatively, two benzyl radicals can dimerize affording the overall silylated pinacol coupling products.[21] We have previously demonstrated that very little silane is converted in a highly related system, but where no aldehyde or other reagent is present to consume the silyl radicals.[13] Accordingly, the initial cleavage of the H-Si bond by $\mathrm{Ni}_{1} \mathrm{Co}_{1} @ \mathrm{NC}$ can be reversible under certain conditions. Reversibility or a late transition state might account for the moderate kinetic isotope effect observed. Finally, a pressure build-up in the reaction vessel was observed which corresponds to the release of $\mathrm{H}_{2}$ from $\mathrm{Ni}_{1} \mathrm{Co}_{1} @ \mathrm{NC} .[22,23]$

Scheme 7. Catalytic Cycle Proceeding through an Initial Formation of Silyl Radicals. RDS = Rate-Determining Step. For the sake of simplicity all steps are drawn as irreversible.

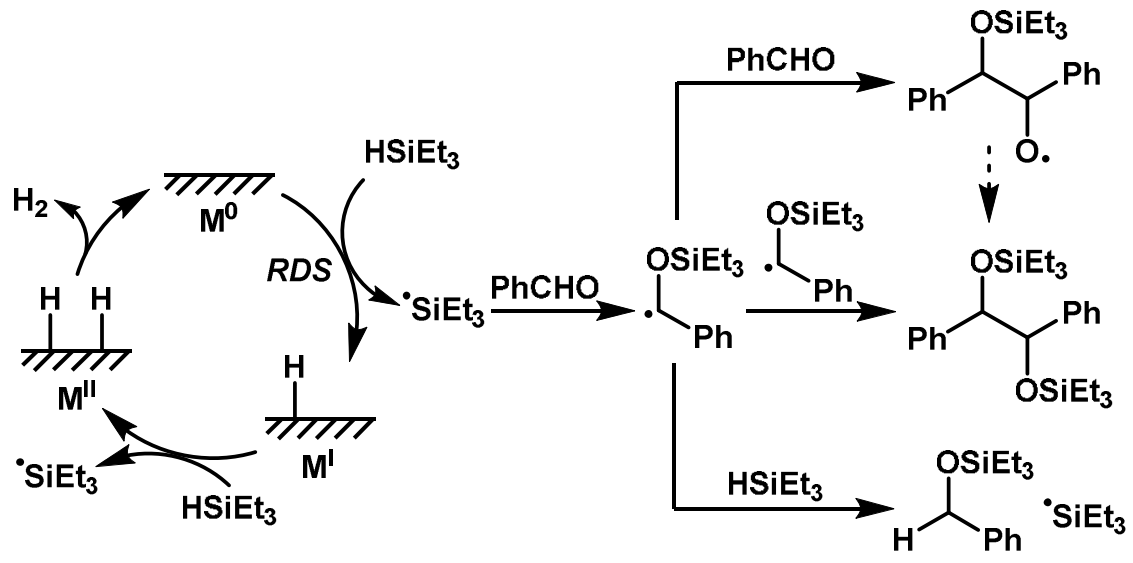

Due to the proposed formation of silyl radicals, hydrosilylation of benzophenone was attempted for a comparison with the much more elaborate conditions in Scheme 1b. Gratifyingly, when benzophenone was subjected to our simplified catalytic conditions, the corresponding hydrosilylation product was observed in a comparable yield (Scheme 8). 
Scheme 8. Radical Hydrosilylation of Benzophenone under Simplified and Catalytic Conditions

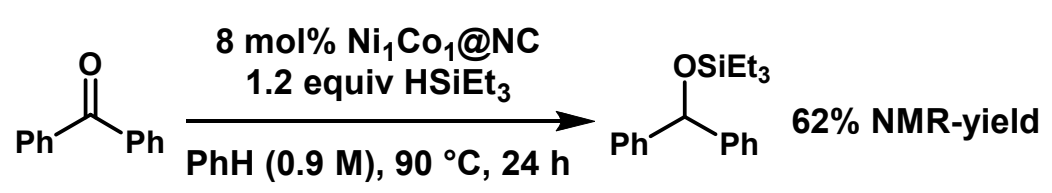

\section{CONCLUSIONS}

In summary, we have developed an improved protocol for the carbon-carbon bond forming pinacol coupling in terms of simplicity, safety, and sustainability. The protocol uses a simple hydrosilane and a stable, recyclable, heterogeneous catalyst, which is based on cheap and earthabundant base metals, thereby circumventing the need for explosive single-use radical initiators and stoichiometric tin reagents. Furthermore, a rare mechanistic investigation, in this field of heterogeneous catalysis, of the operating reaction pathway for the soluble reagents was undertaken. The experimental data include stoichiometric studies, experimental rate orders, kinetic isotope effect, and trapping of silyl radicals. Overall the data are consistent with initial silyl radical formation. This knowledge was applied directly toward the successful radical hydrosilylation of benzophenone. Filtration tests and recycling of the catalyst were also performed, clearly supporting the heterogeneous nature of the catalyst.

A better understanding of the modes of operation for catalysts consisting of base metals supported on nitrogen-doped carbon will be highly valuable for more efficient design of future transformations in this field. Further in-depth studies of reactions with these novel materials are underway in our laboratories.

\section{ASSOCIATED CONTENT}


Supporting Information: Experimental details, characterization data, GC-MS data, NMR spectroscopic data of all products.

\section{AUTHOR INFORMATION}

\section{Corresponding Author}

*skk@kemi.dtu.dk

\section{Notes}

The authors declare no competing financial interest.

\section{ACKNOWLEDGMENT}

The authors gratefully acknowledge the support of the Danish Council for Independent Research, Grant. 6111-00237 and the support from Villum Fonden research grant (13158). We thank Jerrik Mielby for assistance with TEM.

\section{REFERENCES}

(1) Rothenberg, G. Catalysis: Concepts and Green Applications; Wiley-VCH: Weinheim, 2008.

(2) Wang, F.; Mielby, J.; Richter, F. H.; Wang, G.; Prieto, G.; Kasama, T.; Weidenthaler, C.; Bongard, H.-J.; Kegnæs, S.; Fürstner, A.; Schüth, F. Angew. Chem. Int. Ed. 2014, 53, 8645-8648.

(3) For a recent review, see: He, L.; Weniger, F.; Neumann, H.; Beller, M. Angew. Chem. Int. Ed. 2016, 55, $12582-12594$.

(4) (a) Groves, M. N.; Chan, A. S. W.; Malardier-Jugroot, C.; Jugroot, M. Chem. Phys. Lett. 2009, 481, 214-219. (b) Jagadeesh, R. V.; Surkus, A.-E.; Junge, H.; Pohl, M.-M.; Radnik, J.; Rabeah, J.; Huan, H.; Schünemann, V.; Brückner, A.; Beller, M. Science 2013, 342, 1073-1076. 
(c) Zhang, P.; Gong, Y.; Li, H.; Chen, Z.; Wang, Y. Nat. Commun. 2013, 4, 1593. (d) Banerjee, D.; Jagadeesh, R. V.; Junge, K.; Pohl, M.-M.; Radnik, J.; Brückner, A.; Beller, M. Angew. Chem. Int. Ed. 2014, 53, 4359-4363. (e) Zhong, W.; Liu, H.; Bai, C.; Liao, S.; Li, Y. ACS Catal. 2015, 5, 1850-1856. (f) Iosub, A. V.; Stahl, S. S. Org. Lett. 2015, 17, 4404-4407. (g) Arrigo, R.; Schuster, M. E.; Xie, Z.; Yi, Y.; Wowsnick, G.; Sun, L. L.; Hermann, K. E.; Friedrich, M.; Kast, P.; Hävecker, M.; Knop-Gericke, A.; Schlögl, R. ACS Catal. 2015, 5, 2740-2753. (h) Zhang, L.; Wang, A.; Wang, W.; Huang, Y.; Liu, X.; Miao, S.; Liu, J.; Zhang, T. ACS Catal. 2015, 5, 65636572. (i) Xia, W. Catal. Sci. Technol. 2016, 6, 630-644. (j) Jagadeesh, R. V.; Stemmler, T.; Surkus, A.-E.; Junge, H.; Beller, M. Nat. Protoc. 2015, 10, 548-557. (k) Liu, L.; Concepcion, P.; Corma, A. J. Catal. 2016, 340, 1-9. (1) Liu, W.; Zhang, L.; Yan, W.; Liu, X.; Yang, X.; Miao, S.; Wang, W.; Wang, A.; Zhang, T. Chem. Sci. 2016, 7, 5758-5764.

(5) For a recent mechanistic investigation, which does include the solution phase reagents, of a reaction using a Co@NC catalyst, see: Formenti, D.; Ferretti, F.; Topf, C.; Surkus, A.-E.; Pohl, M.-M.; Radnik, J.; Schneider, M.; Junge, K.; Beller, M.; Ragaini, F. J. Catal. 2017, 351, 79-89.

(6) (a) Metal-Catalyzed Cross-Coupling Reactions and More; de Meijere, A.; Bräse, S.; Oestreich, M., Eds.; Wiley-VCH, 2014. (b) Trnka, T. M.; Grubbs, R. H. Acc. Chem. Res. 2001, $34,18-29$.

(7) (a) Kolb, H. C.; VanNieuwenhze, M. S.; Sharpless, K. B. Chem. Rev. 1994, 94, 2483-2547.

(b) Döbler, C.; Mehltretter, G. M.; Sundermeier, U.; Beller, M. J. Organomet. Chem. 2001, 621, $70-76$.

(8) Hirao, T. in Metal Catalyzed Reductive $C-C$ bond Formation; Ed. Krische M. J., Ed; Topics in Current Chemistry; Springer-Verlag: Berlin, 2007; Vol. 279, pp 53-75. 
(9) For leading references and recent examples, see: (a) Hays, D. S.; Fu, G. C. J. Am. Chem. Soc. 1995, 117, 7283-7284. (b) With, T. Angew. Chem. Int. Ed. Engl. 1996, 35, 61-63. (c) Freudenberger, J. H.; Konradi, A. W.; Pedersen, S. F. J. Am. Chem. Soc. 1989, 111, 8014-8016. (d) Nakajima, M.; Fava, E.; Loescher, S.; Jiang, Z.; Rueping, M. Angew. Chem. Int. Ed. 2015, 54, 8828-8832. (e) Okamoto, S.; Kojiyama, K.; Tsujioka, H.; Sudo, A. Chem. Commun. 2016, $52,11339-11342$.

(10) Nishiyama, Y.; Kajimoto, H.; Kotani, K.; Nishida, T.; Sonoda, N. J. Org. Chem. 2002, 67, 5696-5700.

(11) Prices from SigmaAldrich.com: $\mathrm{HSi}(\mathrm{TMS})_{3}$ is $4238 \mathrm{EUR} / \mathrm{mol} \mathrm{HSiEt}_{3}$ is $116 \mathrm{EUR} / \mathrm{mol}$.

(12) Deng, J.; Ren, R.; Deng, D.; Bao, X. Angew. Chem. Int. Ed. 2015, 54, 2100-2104.

(13) Kramer, S.; Mielby, J.; Buss, K.; Kasama, T.; Kegnæs, S. ChemCatChem 2017, 9, 29302934.

(14) When using a catalyst batch that had been stored for six weeks under air at ambient temperature, a small decrease in activity and selectivity was observed ( $89 \%$ conversion, $54 \% 1$ a, $34 \% 2)$.

(15) See Supporting Information for additional details.

(16) The amount of metal in the filtrate was examined by ICP-OES. The filtrate contained 6 ppm nickel and 17 ppm cobalt.

(17) Except for para-OMe, the yields and stereoselectivities are comparable to recent reports using photoredox catalysis (references 9d-e). 
(18) (a) Zhou, W.; Marquard, S. L.; Bezpalko, M. W.; Foxman, B. M.; Thomas, C. M. Organometallics 2013, 32, 1766-1772. (b) Mukhopadhyay, T. K.; Rock, C. L.; Hong, M.; Ashley, D. C.; Groy, T. L.; Baik, M.-H.; Trovitch, R. J. J. Am. Chem. Soc. 2017, 139, 49014915.

(19) Nador, F.; Mascaro, E.; Castro, M.; Vitale, C.; Radivoy, G. Arkivoc 2011, 312-326.

(20) The exact role of benzoic acid is unclear. The influence on selectivity suggests an interaction with the substrates or intermediates. A role in the hydrogen evolution is also possible.

(21) To probe for a possible selectivity-determining step involving the arylaldehyde, a competitive Hammett study was attempted by independently reacting three different parasubstituted arylaldehydes $\left(t-\mathrm{Bu}, \mathrm{F}\right.$, and $\left.\mathrm{CF}_{3}\right)$ in competition with benzaldehyde. While the correlation with $\sigma^{\bullet}$ was much better than $\sigma_{\text {para }}$, the error on the linear correlation was significant $\left(\mathrm{R}^{2}=0.22\right.$ for $\sigma^{\bullet} ; \mathrm{R}^{2}=0.004$ for $\left.\sigma_{\text {para }}\right)$. These results could indicate that the pathway after addition of the silyl radical to the arylaldehyde is not a simple dimerization of siloxybenzyl radicals.

(22) A related mechanism has been proposed for a heterogeneous gold-catalyzed reaction; however, the reaction mechanism was merely speculative, based only on the observed silylative pinacol product, and not supported by any mechanistic evidence. The isolated yield of $\mathbf{1 a}$ with this precious metal catalyst was 32\% (95\% conversion) for the analogous reaction: Raffa, P.; Evangelisti, C.; Vitulli, G.; Salvadori, P. Tetrahedron Lett. 2008, 49, 3221-3224.

(23) The reaction mechanism proposed for our heterogeneous system displays many similarities to a recent homogeneous system for $\mathrm{HSiEt}_{3}$ activation: (a) Toutov, A. A.; Liu, W.-B.; Betz, K. 
N.; Fedorov, A.; Stoltz, B. M.; Grubbs, R. H. Nature 2015, 518, 80-84. (b) Liu, W.-B.; Schuman, D. P.; Yang, Y.-F.; Toutov, A. A.; Liang, Y.; Klare, H. F. T.; Nesnas, N.; Oestreich, M.; Blackmond, D. G.; Virgil, S. C.; Banerjee, S.; Zare, R. N.; Grubbs, R. H.; Houk, K. N.; Stoltz, B. M. J. Am. Chem. Soc. 2017, 139, 6867-6879.

\section{TOC graphic}

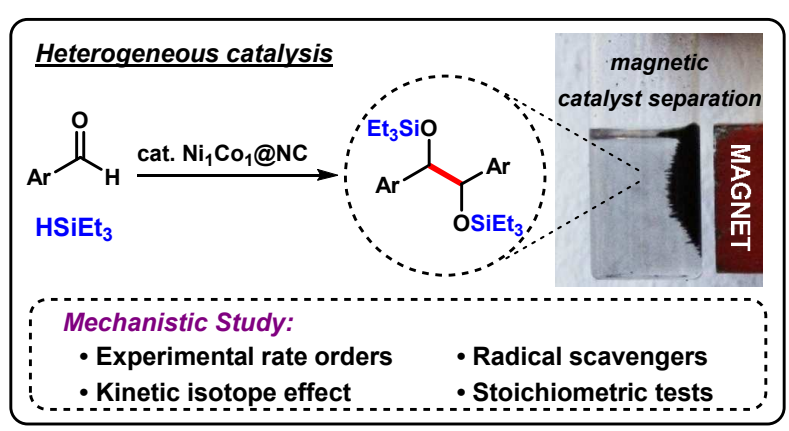




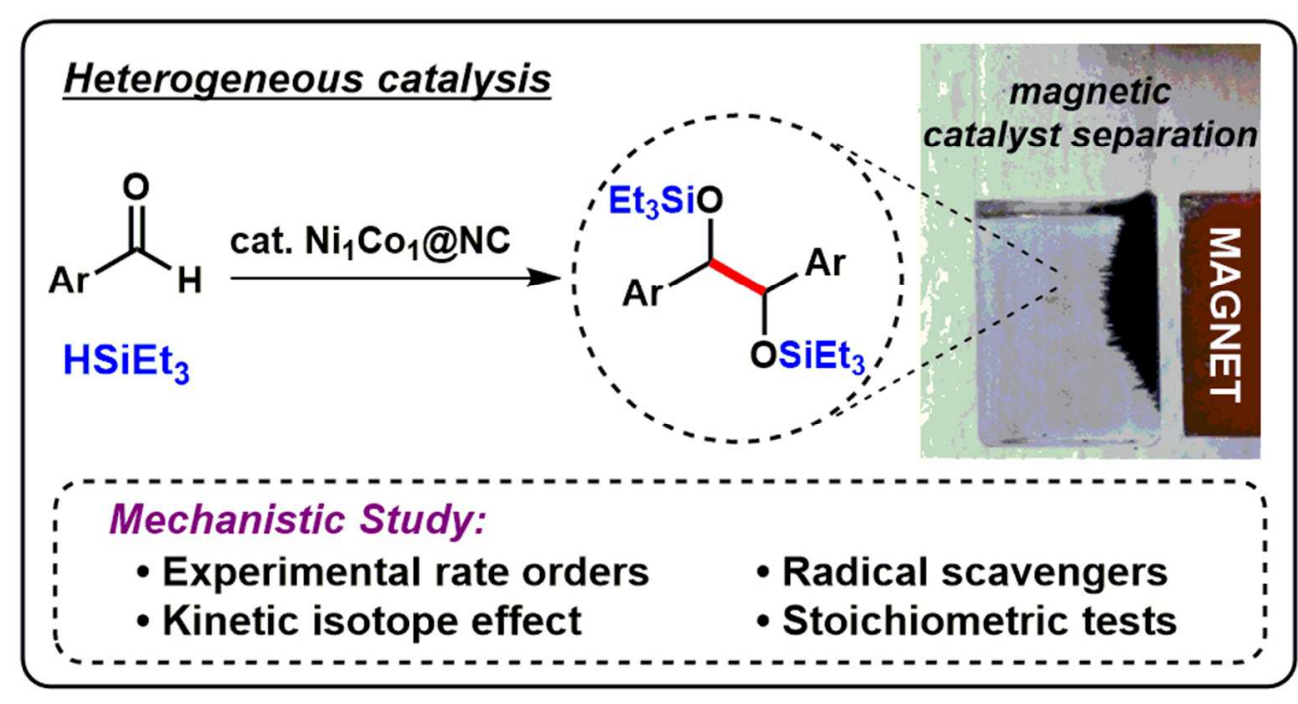

$80 \times 43 \mathrm{~mm}(300 \times 300$ DPI $)$ 
a) Classical methods for pinacol coupling

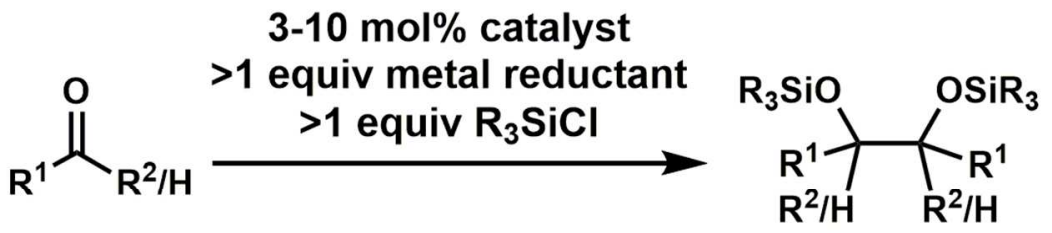

b) Hydrosilylation through addition of silyl radicals to ketones $10 \mathrm{~mol} \%$ AIBN<smiles>COC(c1ccccc1)P(c1ccccc1)c1ccccc1</smiles>

(a) Classical approach to pinacol coupling. (b) Typical reaction conditions for accessing silyl radicals $113 \times 57 \mathrm{~mm}(300 \times 300 \mathrm{DPI})$ 


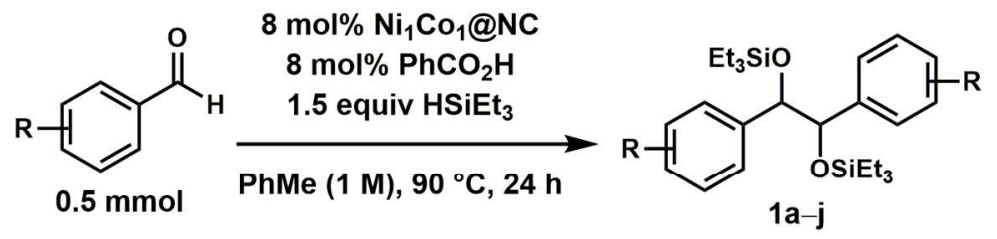<smiles>CCOC(c1ccccc1)C(OCC)c1ccccc1</smiles>

1a, $68 \%$<smiles>CCCc1ccc(C(OCC)C(OCC)c2ccc(C(C)C)cc2)cc1</smiles>
1c, $80 \%$<smiles>CCOC(c1cccc(F)c1)C(OCC)C(OCC)c1cccc(F)c1</smiles>
$1 \mathrm{e}, 66 \%$<smiles>CCOC(c1ccc(C(F)(F)F)cc1)C(OCC)c1ccc(C(F)(F)F)cc1</smiles><smiles>CCOC(c1ccc(OC)cc1)C(OCC)c1ccc(OC)cc1</smiles><smiles>CCOC(c1ccc(C(C)(C)C)cc1)C(OCC)C(OCC)c1ccc(C(C)(C)C)cc1</smiles>

$1 \mathrm{~b}, 79 \%$<smiles>CCOC(c1ccc(-c2ccccc2)cc1)C(OCC)c1ccc(-c2ccccc2)cc1</smiles>

1d, $72 \%$<smiles>CCOC(c1ccc(F)cc1)C(OCC)c1ccc(F)cc1</smiles><smiles>CCOC(c1cccc(Cl)c1)C(OCC)c1cccc(Cl)c1</smiles>

1h, $73 \%$<smiles>CCOC(c1ccncc1)C(OCC)C(OCC)c1ccncc1</smiles>

${ }^{a}$ Isolated yield of purified product. ${ }^{b}$ NMR yield.

Influence of Functional Groups on the Reaction Outcome ${ }^{a}$ $116 \times 185 \mathrm{~mm}(300 \times 300 \mathrm{DPI})$ 


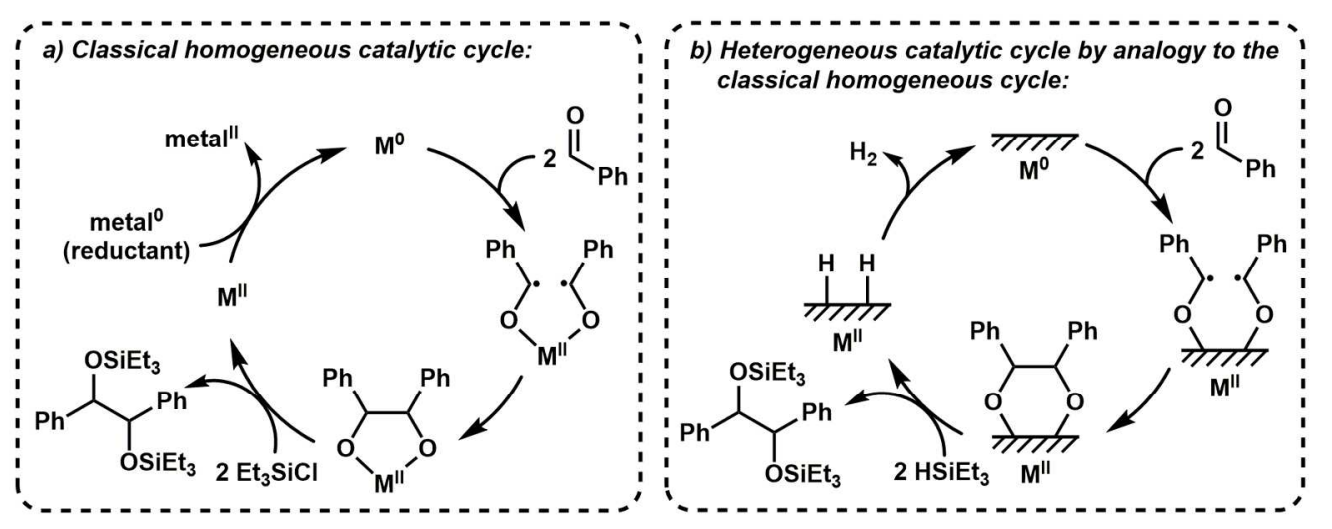

Classical Catalytic Cycles Proceeding through an Initial Pinacol Coupling Followed by Silylation $166 \times 64 \mathrm{~mm}(300 \times 300 \mathrm{DPI})$ 
a) Stoichiometric reaction without silane

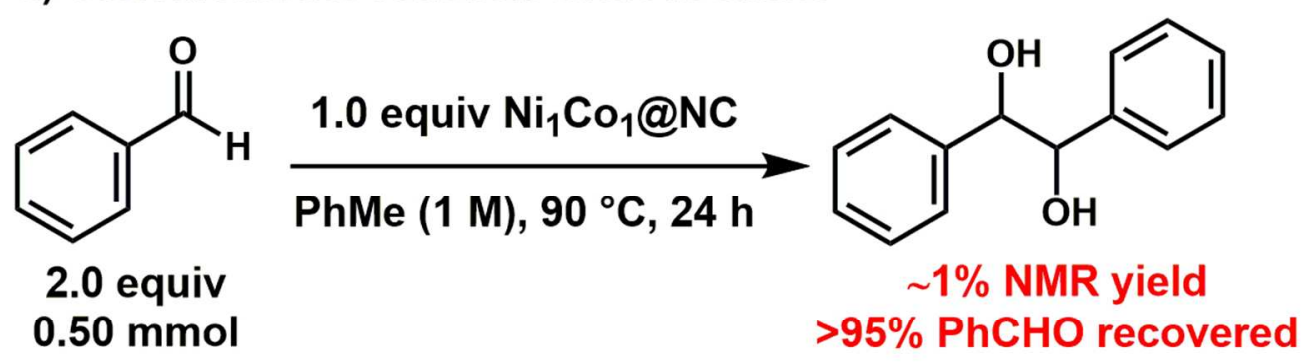

b) Testing for chemical competence of pinacol intermediate

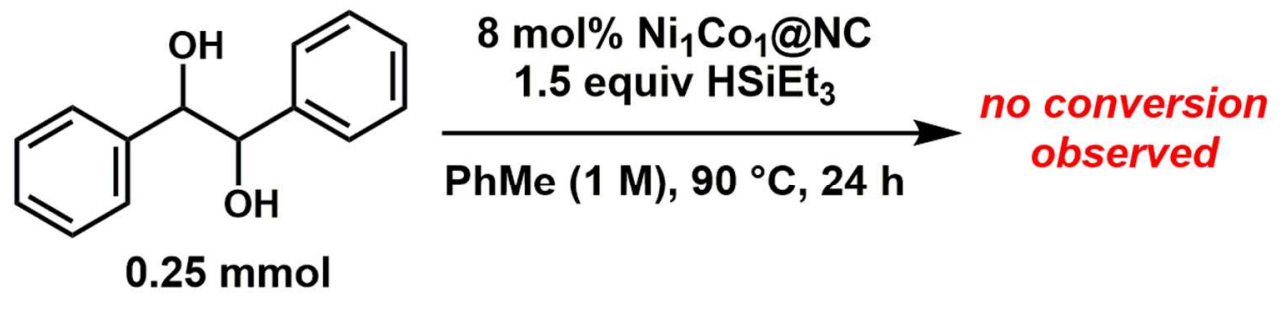
Stoichiometric Studies $103 \times 68 \mathrm{~mm}(300 \times 300 \mathrm{DPI})$ 

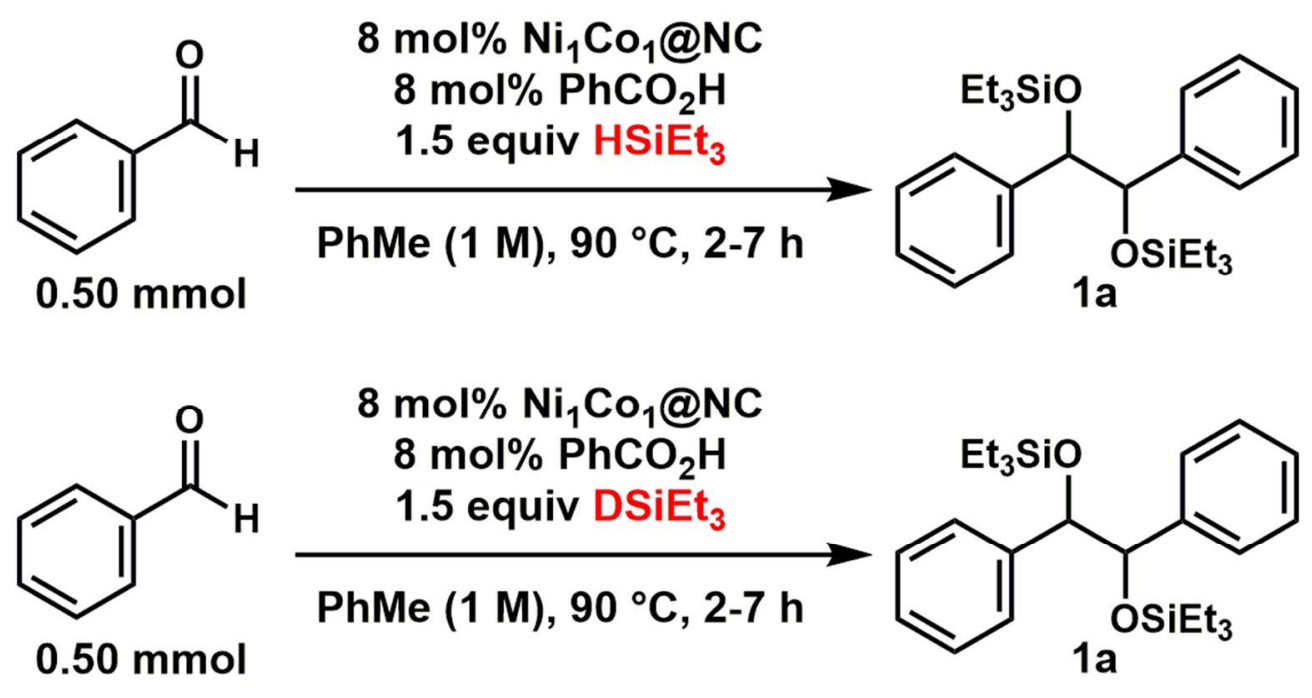

$K I E=1.9$ (initial rates in separate vessels)

Detection of Kinetic Isotope Effect by Independent Rate Measurements

$96 \times 59 \mathrm{~mm}(300 \times 300 \mathrm{DPI})$ 
a)<smiles>O=Cc1ccccc1</smiles><smiles>CC1(C)CCCC(C)(C)N1[O]</smiles>
0.5 equiv (TEMPO)

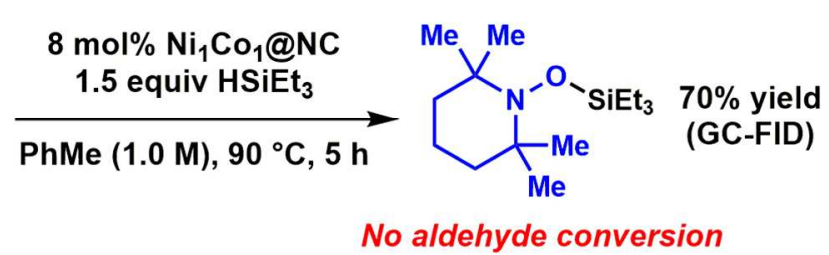

b)

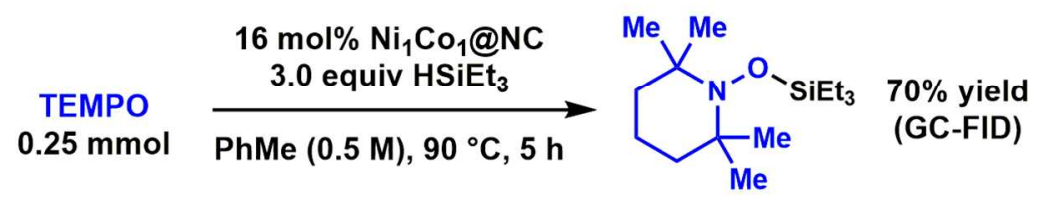

c)

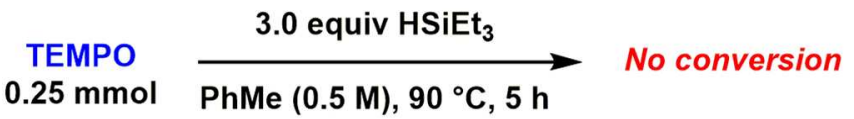

Experiments with TEMPO demonstrated Rapid Formation of TEMPO-SiEt3 in the Presence of Ni1Co1@NC $131 \times 69 \mathrm{~mm}(300 \times 300$ DPI $)$ 


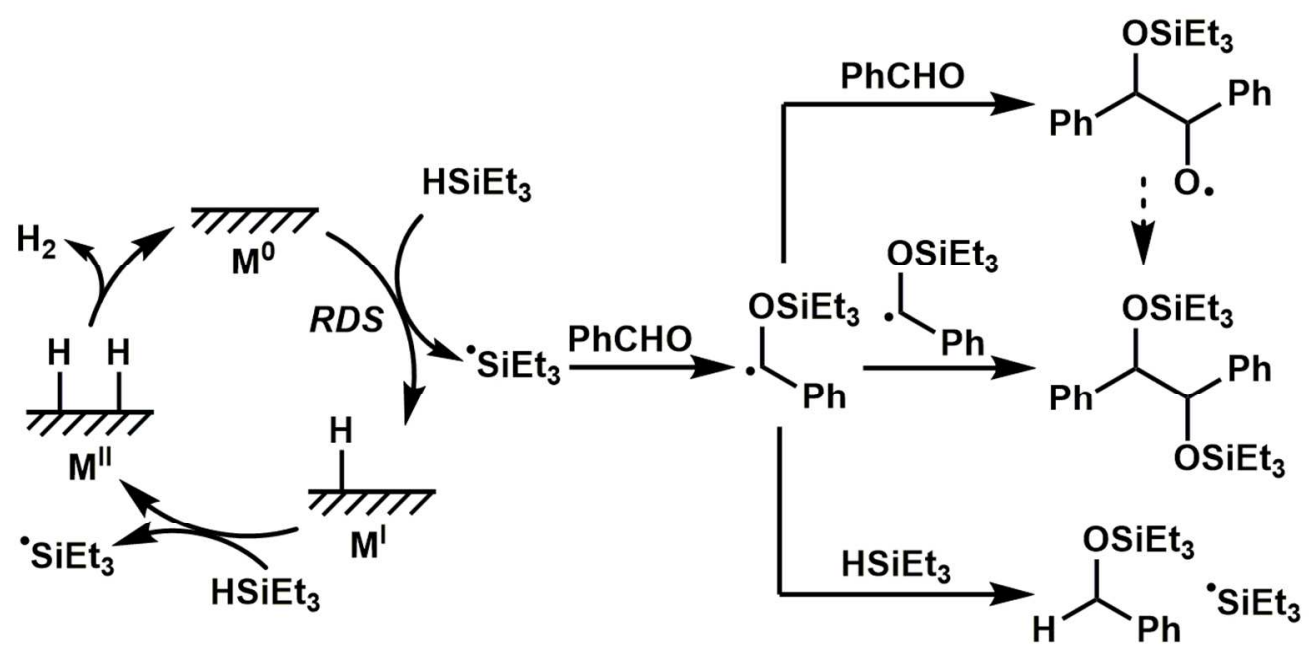

Catalytic Cycle Proceeding through an Initial Formation of Silyl Radicals. RDS = Rate-Determining Step. For the sake of simplicity all steps are drawn as irreversible

$114 \times 56 \mathrm{~mm}(300 \times 300$ DPI $)$ 


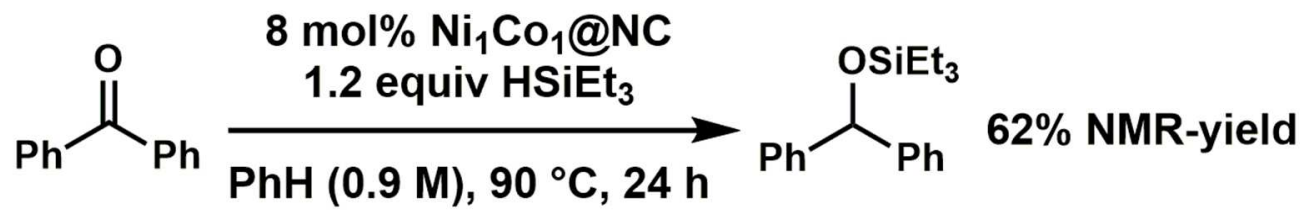

Radical Hydrosilylation of Benzophenone under Simplified and Catalytic Conditions $105 \times 18 \mathrm{~mm}(300 \times 300 \mathrm{DPI})$ 


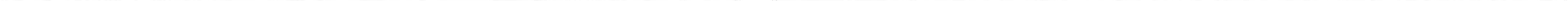




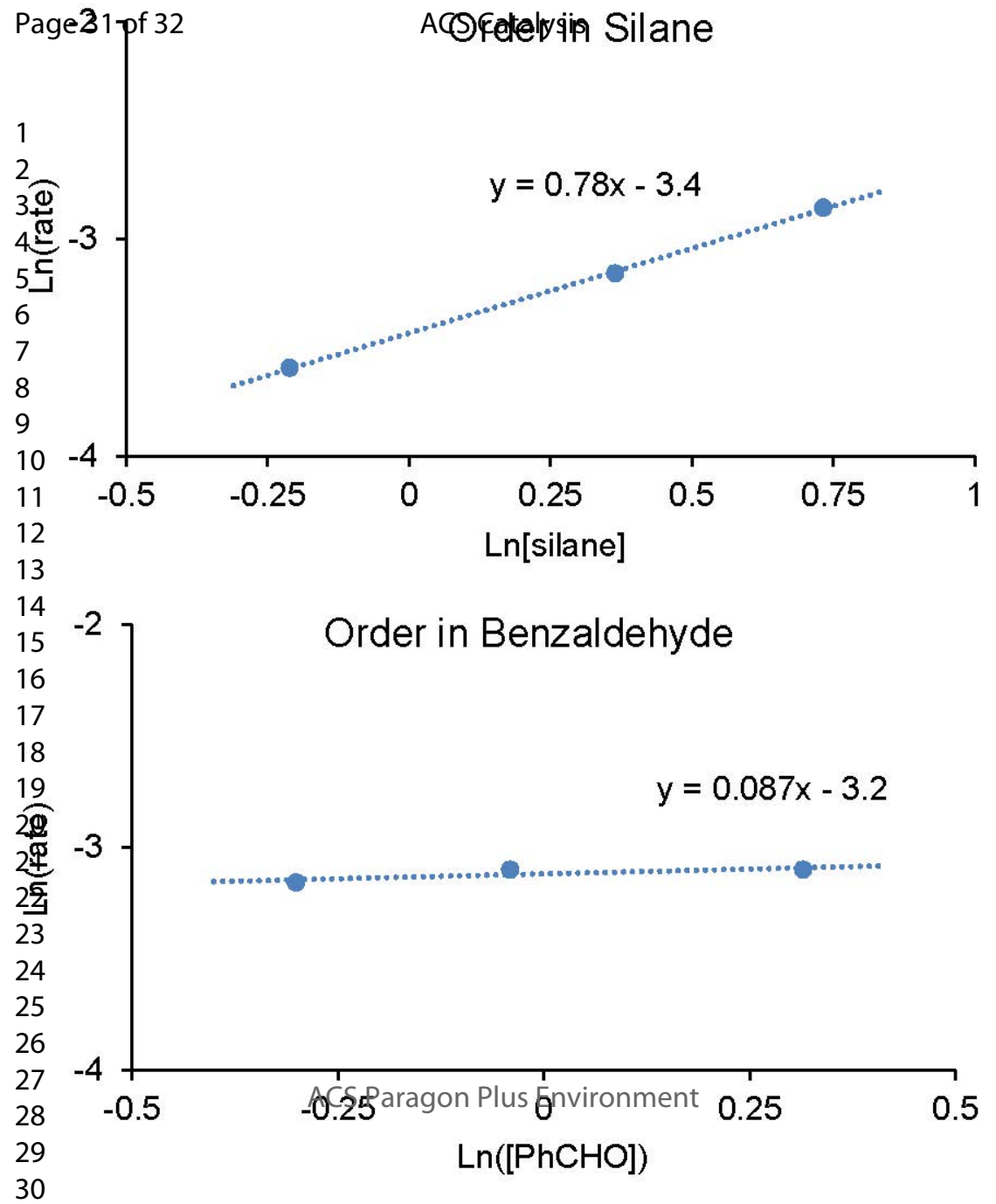

